\title{
Factors Affecting ESL Students' Willingness to Communicate in English Classroom Discussions and Their Use of Linguistic Strategies
}

\author{
Maryam Jahedi, Lilliati Ismail* \\ Department of Language and Humanities Education, Faculty of Educational Studies, Universiti Putra Malaysia, Malaysia
}

Received March 29, 2020; Revised May 20, 2020; Accepted May 27, 2020

Copyright $(2020$ by authors, all rights reserved. Authors agree that this article remains permanently open access under the terms of the Creative Commons Attribution License 4.0 International License

\begin{abstract}
In the past few years, the importance of willingness to communicate (WTC) has received greater attention among scholars in the field as it has generally been found that WTC is closely related to the development of linguistic competence. This study employed the WTC Model (MacIntyre et al., 1998) and Halliday's (1985) Systemic Functional Linguistics to examine Malaysian students' WTC behavior through the analysis of classroom observations, journal entries and interview data. Thematic analysis was used to identify the situational factors affecting students' WTC in classroom discussion interactions. Moreover, linguistic analysis of the data concentrated on interpersonal meaning of tenor to find out how students' WTC was realized and how role relations were established among them through mood patterns and speech functions. The study found the major factors that increased the students' WTC in the classroom discussions including topics of interest, relevance of the topic to one's experience, teaching method, the relationship with peers, etc. Furthermore, the findings revealed that the students' WTC was realized linguistically through the predominant use of declarative and interrogative discourse. Moreover, students tended to react more through supporting moves rather than confronting moves which showed a cooperative and positive atmosphere in the classroom. It can be concluded that students' WTC in a particular situation is related to certain factors that promote their behavioral WTC to be manifested through language.
\end{abstract}

Keywords L2 Learners, Situational Factors of WTC, Speech Functions, Systemic Functional Linguistics, Willingness to Communicate

\section{Introduction}

Over the past few years, the importance of willingness to communicate (WTC) in the second language (L2) has been given particular importance and studies have tried to find ways to promote learners' WTC, especially in classroom interactions. WTC is "conceptualized as a readiness to speak in the L2 at a particular time with a specific person, and as such, is the final psychological step to the initiation of L2 communication" (MacIntyre \& Doucette, 2010, p. 162). Learners who do not participate in the second language interaction are considered passive and unmotivated (Cao, 2009). Therefore, there is a concern for the students who are unwilling to communicate in the L2 (MacIntyre, \& Doucett, 2010) since lack of English proficiency can put them at a disadvantage in the job market (Nair et al., 2012). In order for students to reach the desired level of English proficiency, there is a need to encourage them to communicate more in the English language (Yousef, Jamil \& Razak, 2013).

As WTC is related to language teaching and learning, it is important to examine it in ESL or EFL classroom-based contexts (Abd Rahman, Abd Samad \& Abu Bakar, 2020; Cao, 2009; Riasati \& Noordin, 2011; Manipuspika, 2018; Riasati, 2018). Studies on WTC "centered mainly on the use of structural models and trait, self-reported measurements of WTC, but recent research has shown that WTC is also heavily dependent on the situation" (Robson, 2015, iii); yet, situational variables have not been addressed adequately (Yashima, MacIntyre \& Ikeda, 2018). Moreover, WTC as a construct is treated more as "a measure of whether someone will initiate talk rather than how much the person actually speaks" (Dörnyei \& Kormos, 2000 , p. 286). Although the use of certain linguistic means and strategies contribute to students' WTC in the English language classroom which can increase their English proficiency level (Nakatani, 2006), research on WTC from the linguistic point of view is scarce. Understanding the linguistic choices made by students to manifest their WTC can help English learners to "utilize their existing 
knowledge to reach their communicative goal more effectively" (Omar et al., 2012, p. 536).

Considering the aforementioned problems, the study aimed to investigate Malaysian TESL students' WTC in class discussion interactions to discover not only the factors that can increase their willingness to communicate in the L2 classroom but to find the linguistic strategies used by the students to manifest WTC. Malaysian students were chosen as the participants for the present research since according to previous research they "have a high degree of L2 communication apprehension" (Yousef et al., 2013, p. 207) and limited English communication skills (Darmi, \& Albion, 2014) which inhibit their WTC. Nevertheless, there is a dearth of research on students' WTC in the Malaysian context (Kho-Yar, Rafik-Galea \& Kho, 2018). While there are limitations related to the sample size and generalizability of findings, the researchers tried to increase the transferability of the results through the thick description of data collection and data analysis procedures as advocated by Lincoln and Guba $(1985$, p. 316) who stated that "as the naturalist cannot specify the external validity of an enquiry, he or she can only provide the thick description necessary to enable someone interested in making transfer to reach a conclusion about whether the transfer can be contemplated as a possibility."

The researchers believe that the findings of the study will benefit L2 learners since the affective factors to WTC can be identified which will help them to increase their engagement in classroom interactions and, thus, help them to be more efficient and proficient in language use and communication. Furthermore, identifying linguistic choices made by the learners to manifest their WTC plays a significant role in language pedagogy as the school authorities, policy makers and material designers can be aware of the linguistic and communicative needs of the learners to improve the school curriculum.

The research questions are as follows:

RQ1: What situational factors may affect the Malaysian students' WTC in classroom discussion interactions?

RQ2: What linguistic strategies are used by the students to realize their WTC in classroom discussion interactions?

\section{Theoretical Background}

This study used a combination of theories and analytical tools proposed by prominent scholars in the field such as MacIntyre, et al.'s (1998) WTC model and Halliday's (1985) Systemic Functional Linguistics (SFL) to study Malaysian students' WTC in the classroom context to find the factors affecting their willingness to communicate and to identify linguistic means used to manifest their WTC. The pyramid model of WTC which is presented in Figure 1 provides twelve linguistic, communicative and socio-psychological variables which "account for individual differences in the decision to initiate L2 communication" (MacIntyre et al., 2001, p. 370).

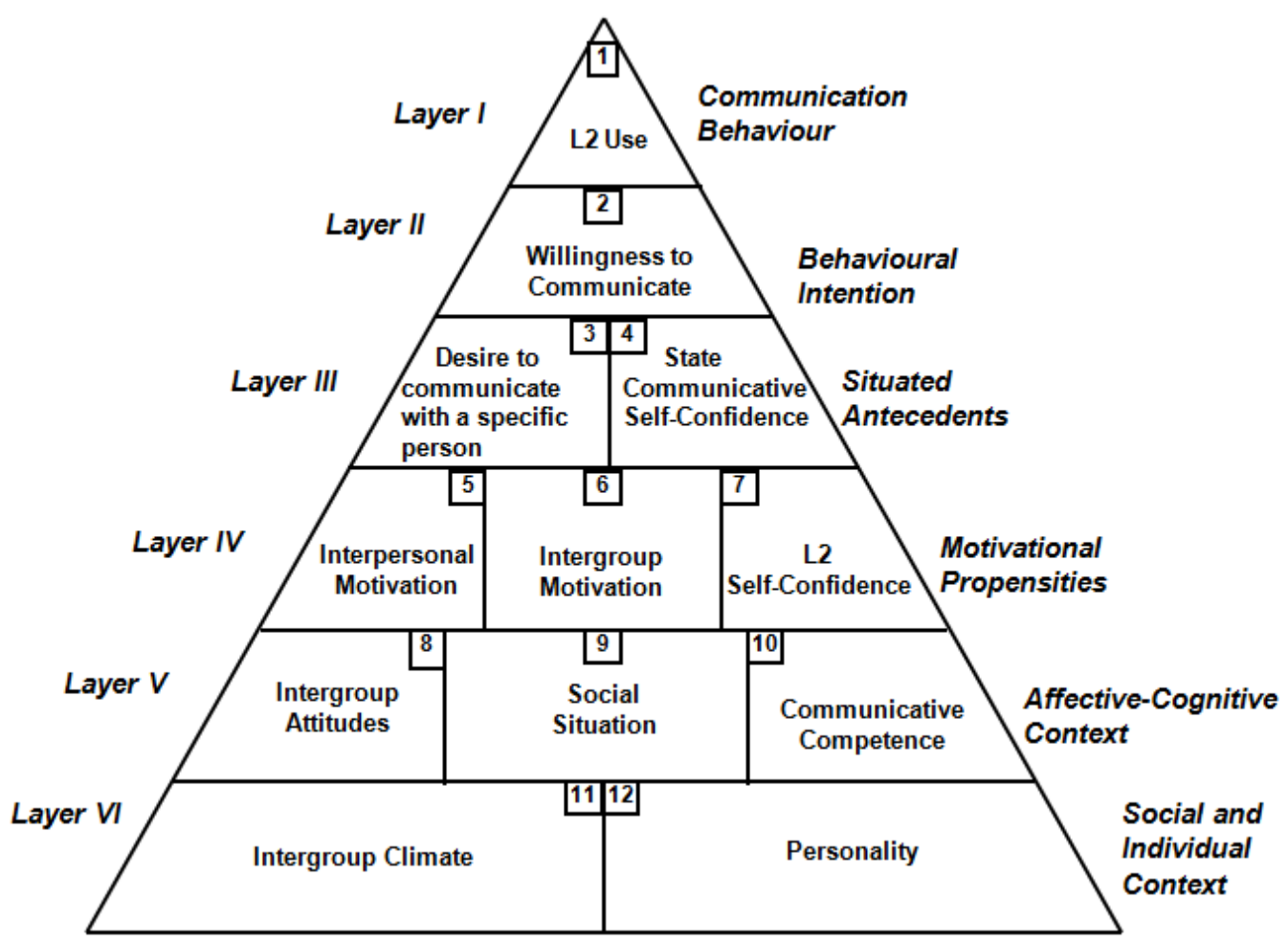

Figure 1. Heuristic Model of Variables Influencing WTC (MacIntyre et al., 1998, p. 547) 
The WTC model includes six layers with 12 variables. The three top layers, including Communication Behavior, Behavioral Intention and Situated Antecedents are situational factors which are momentary and dependent on the specific context, whereas the three layers at the bottom, including Motivational Propensities, Affective-Cognitive Context and Societal and Individual Context are trait-like factors which have enduring influences on learners' WTC.

By drawing on the WTC model and bearing in mind why a person is willing to communicate at one time but not at another time, it is possible to appreciate the factors affecting willingness to participate in classroom discussions. As the main objective of the study was to focus on the students' WTC in the classroom context, the study was mainly concerned with the situated characteristics to WTC rather than the trait-like characteristics as the trait-like WTC "is not necessarily predictive of actual classroom behavior. Rather, WTC may be strengthened or weakened according to factors associated with the specific situation" (Cao \& Philp, 2006, p. 489). The situational factors in the model can explain "why some learners speak in spite of limited communicative competence, while others are quite reluctant to talk even with high competence;" (MacIntyre, et al., 1998, p. 558). Moreover, Halliday's (1985; 1994) Systemic Functional Linguistics has been employed due to its "social and context-embedded features" (Muller \& Willson, 2008, p. 767). SFL can play a significant role in describing the enactment of learners' WTC in the discussion discourse since it considers meaning and language functions as the foundation of communicative activities. As Jacob and Ward (2000) stated, "Systemic Functional Linguistics focuses on the way in which language serves as a tool for communication and on how people choose which bits of language to deploy" (p. 5). Therefore, SFL was used to analyze language use or functions and to describe how linguistic choices made by the learners contribute to the realization of their WTC in the classroom discussion discourse. Therefore, to examine the realization of WTC and to uncover how role relations were established among the participants, the study concentrated on mood patterns and speech functions.

\section{Methods}

\subsection{Participants}

This research used purposive sampling to concentrate on a small group of participants which include six students studying in a public university in Malaysia, which is the place where the research was conducted and all the students were also willing to participate in the research. Moreover, purposive sampling was employed to choose students in the Teaching of English as a Second Language (TESL) program taking the Advanced
Communication course since the purpose of this study was to examine their actual WTC realized linguistically. Therefore, it was a requirement that the participants should have a good command of the English language to achieve the research purpose.

\subsection{Instruments}

In this study, multiple instruments such as non-participant observations, journal entries, and a semi-structured interview were used to look at students' willingness to communicate in discussion interactions over one semester. Non-participant classroom observations were used to focus on students participating in discussion interactions within one semester. Three observation discussions were randomly selected and transcribed using transcription conventions adapted from Eggins and Slade (1997) which enabled the researchers to collect linguistic data to analyze the students' use of linguistic choices made to realize their WTC. Moreover, the students were asked to keep a journal entry about their WTC in those particular classroom discussions. Then, the researchers collected the journal entries from the students via email for the thematic analysis. Finally, a follow-up semi-structured interview was conducted on week 13 to triangulate the data. The analysis of the students' diary and interview data enabled the researchers to uncover the variables affecting their WTC in classroom discussions.

\subsection{Data Analysis Procedure}

Following the steps by Braun and Clarke (2006), the study applied a thematic analysis of the data to discover the emerging themes and patterns of the students' WTC. First, the researchers (re)read the journal entries and interview data to be more familiar with the data and to note down the primary ideas. Next, the study focused on coding the data based on theoretical perspectives (Creswell, 2008, Miles \& Huberman 1994) and organized them into sets of categories to focus "on interpreting information that sheds light on the study question" (McNabb, 2015, p. 75). Then, the codes were collated into themes based on which the relevant data were gathered. Further, the themes were checked and reviewed in order to define them and to give clear names. Then, descriptive analysis concentrated on recurrent themes and patterns. Finally, the data were interpreted to answer the first research question and reach to conclusions.

Furthermore, the linguistic analysis of the observation transcripts of the classroom discussions was carried out to find the linguistic strategies used by the students to realize their WTC. The analysis of speech functions was carried out to identify the role of the speakers through the move choices such as initiation, response, supporting (i.e. acceptance, undertaking, acknowledgement and answer) or confronting (i.e. rejection, refusal, contradiction and 
disclaimer) which may be linked to their willingness to participate in discussions. Further, mood analysis was used to identify clause types such as declaratives, interrogatives and imperatives to indicate the degrees of interpersonal relations among the students such as dependency, closeness and authority (Egging \& Slade, 2004).

\section{Results and Discussions}

\subsection{Thematic Analysis of Students' WTC Behavior: Situational Factors}

The analysis of data from the students' journal entries and interview data concerning their perceptions on WTC in classroom discussions has identified some situational factors, including topics of interest, relevance of topic to one's experience, teaching method, the relationship with peers, peers' points of view, positive feedback, the role of the moderator, the size of the classroom, English competency and the fear of being ridiculed/judged. The factors affecting the students' WTC along with the evidence found in the data are presented below. The examples taken from the data are shown with an English letter representing each participant.

\subsubsection{Topics of Interest}

Topic of interest was identified as a factor enhancing the students' WTC since they were willing to interact in discussions for the reason that the topic was interesting, remarkable, encouraging and easy to understand without being left behind. The following statements provide good examples of their perceptions regarding the topic of the discussions.

- R. ...talking about a topic that is really interesting to me.

- C. When I was reading the text, I found it to be a very interesting read... Not even once I felt left out during the discussion because the topics discussed was very interesting.

- Q. The topic was remarkable to me.

- $\quad$ E. I am honestly very happy with the topic that was chosen for today's lesson.

- Y. The topic that was being discussed on the last Socratic discussion was very interesting.... Thus this topic encouraged me to talk further and give my opinion.

\subsubsection{Relevance of the Topic to One's Experience}

The relevance of topic to the students' experience or background was seen as a factor that enable them to engage in the discussions as they believed that their contributions were depended on their own experience related to the topic and their ability to relate the topic to their own situations, opinions and background. These are shown in the following examples:
- R. I was reminded of my own experience dealing with my nephews who loves to question things.

- Y. The topic actually quite close to me and I was able to relate to the topic and able to talk on my point of view.

- C. It's a topic where everyone can and will communicate as it relied heavily on one's background and opinions.

- Q. I was able to relate the topic of the discussion to my own situation as well.

- C. The topic discussed didn't require extensive research but more to relating to experience, which makes it easier to engage in the discussion.

- E. The class today discussed many issues which were pertinent and at the same time very relevant to me.

\subsubsection{Teaching Method}

Teaching method is another influencing factor to WTC as it was perceived as a helpful and motivating method since it allowed the students to participate in discussions without their answers being judged as wrong or right and, thus, it could give them confidence to share their opinions. These are shown in the following examples:

- R. The group discussion was done in a manner that people are receptive and that there is no judgment in whatever point that were brought up.

- Y. Before the discussion starts, the technique of taking turn to read aloud the story was very helpful.... the reading activity actually helped me get warmed up for the discussion.

- E. The fact that Socratic discussion allows you to contribute without any wrong or right answers made me feel even more motivated to contribute.

- Y. The nature of Socratic discussion too gave me the confidence to participate. It is because Socratic discussion is all about sharing our stand and opinion with others.

\subsubsection{The Relationship with Peers}

Another factor that made them more willing to communicate in discussions was their relationships with their course mates as they felt a close rapport and respect leading to a comfortable and relaxed environment that made it easy for them to contribute and share their ideas. The examples are given below:

- C. I really enjoy learning with my classmates, having them in the class, you know. We help each other pretty much when it comes to speaking.

- L. I felt comfortable to voice up my opinions because we knew each other and we respect each other.

- Q. I found out that being familiar with my course mates made me more willing to communicate my opinions during the discussion.

- $\quad$ E. The rapport between all my course mates made it 
easier to contribute.

- $\quad$ Y. I did not feel anxious at all during the discussion as I was with a group of friends who I am familiar with.

- $\quad$ R. I met them from the first semester and I know them, so we have a good relationship and if I forget something, they will remind me. It's easier to open up because of our good relationship.

\subsubsection{Peers' Points of View}

It was revealed that not only the topic itself, but the opinions of students' course mates on the topic can also motivate them to participate in the discussion. For instance, posing some questions, bringing up some interesting facts and opinions regarding the topic of discussion can encourage their contributions and enhance their WTC. The following examples illustrate this:

- R. My classmates brought up some interesting facts.

- L. I only realized that when other course mates asking some questions or giving their opinions. I had a lot of things to say in the discussion.

- Y. Furthermore, when my other friends started to pose questions, it helped me to think further from the questions that they asked. Y. I was feeling blank and had no answer. When one of the members from the circle started asking question such as 'Is education important?' It was where the question triggering me to think from different angle.

- C. Even though at first I had not enough substance to elaborate further on my ideas, but after listening to my classmates, I was able to communicate alongside them. There is one particular question that got me hooked into the discussion.... that question had actually made everyone to contribute their honest thoughts and opinions...The other questions that followed through had made the entire discussion whole lot meaningful.

- Q. Everyone's points of view were very appealing to me.

\subsubsection{Positive Feedback}

Positive feedback of peers was identified as another factor that contributed to students' interactions. Knowing that their opinions are respected and appreciated by their course mates and no one would challenge their ideas, made a comfortable environment for the students to put their ideas forward without the fear of being judged.

- $\quad$ R. I felt free to share my views because I felt that the group discussion was done in a manner that people are receptive and that there is no judgment.

- $\quad$ Y. The members in the discussion group respected each other and accepted that everyone has the rights to put their view forward.

- L. I felt comfortable to voice up my opinions because ... we respect each other.

- $\quad$ E. Our opinions were appreciated and respected. I feel less intimidated to contribute my ideas as I know I would not be judged.

\subsubsection{The Role of the Moderator}

The role of the lecturer as a moderator was highlighted by the students as an important factor which triggered their interests by choosing a good method to prompt questions, guiding the discussion and making it lively.

- C. The choices of Socratic Questioning triggered my interest.

- $\quad$ R. The way the discussion was guided, was very interesting to me.

- Y. I thank the moderator for coming up with interesting card game to introduce psycho-motor element in the discussion.

- L. The moderator plays an important role to make the discussion in the class lively.

- $\quad$ E. ...was able to prompt all of us with questions that made it easier for all of us to connect to the topic and actually discussed.

\subsubsection{The Size of the Class}

The size of the class is perceived as an important factor that affect the students' WTC since a class with a smaller size of students is ideal for communicating as it provides more opportunities for them to participate in discussions, whereas a classroom with more students would make them to speak less or to remain quiet.

- C. A smaller class with fewer students is ideal for discussion because everyone gets to contribute.

- $\quad$ E. I would be able to contribute more if the class is small.

- Q. If the size of class is too big, there will be fewer opportunities for me to communicate and I will choose to not communicate.

- L. I like small group of people so everyone has an opportunity to talk.

- $\quad$ R. If the class has too many students in its chances are I would not be speaking much, because I do not like to fight for my right to speak.

- $\quad$ Y. If there were too many members in the discussion then I will feel obliged to allow others to talk and I would talk lesser.

\subsubsection{English Competency}

Being competent in English was seen as an influencing factor contributing to students' WTC as the knowledge of grammar and vocabulary was appeared to give them more confidence and thus enabled them to express their thoughts, feelings and opinions.

- C. Sometimes the grammar that I use could be wrong. That actually have an effect on me like I say, oh my God, I said the wrong grammar I'm just gonna keep quiet for now.

- $\quad$ E. I don't think I have problems speaking. I'm very 
competent.

- L. Sometimes I will lack of confidence, like, especially when I want to explain something, the vocabs maybe are not in my mind. I don't have the confidence how to explain, how to, like, express my feelings, what's the word that I should use to express my feelings.

- $\quad$ R. I'm able to use and convey my ideas with my friends and share the thoughts without really having to judge of how well I speak.

- $\quad$ Y. I have enough wide range of vocabulary to bring across my message on what I really think I want to say.

\subsubsection{The Fear of Being Ridiculed/Judged}

The fear of being ridiculed or judged is an another important factor to students' WTC. The results of the analysis revealed that students are not able to share their thoughts if they are scared of being ridiculed. They are afraid that if they express their opinions in an unfriendly environment, people might judge them or laugh at their opinions.

- C. If that happens, I don't really wanna talk because I don't want make myself stupid. You know, people would think what's wrong with her, she teaches English, she can't even speak English.

- $\quad$ Q. They judge the opinions, but not the ability to speak. That's what I'm afraid of. I may think that my opinion may not be that suitable. If the opinion is not right then ok you'll become ridiculed, you'll become embarrassed.

- $\quad$ L. We will not be able to share everything with them because maybe we're afraid that, or we're shy maybe, they'll be laugh at me, or maybe at the back, they will say something bad about me.

- $\quad$ R. If it's in the different environment, with not this people, I would be afraid that people would laugh at me.

- Y. I would definitely think twice before taking because at that time the environment was not like accepting whatever you're telling. People started judging you, so I would be very scared that people might juggle me for what I'm telling. Then I might sound funny that I didn't fall to what they expect.

As the analysis of the data has shown, students are more willing to participate in class discussion interactions when the topic being discussed is interesting and related to their experiences which makes them to share their opinions and participate more. The greater the shared knowledge of the students, the higher would be their level of WTC. Another important thing is their relationship with their course mates; familiarity with peers makes them more confident as they feel comfortable to voice up their opinions with the feeling of not being judged and ridiculed. Moreover, peers' points of view and the moderating role of the interlocutor help them to get the ideas on the topic and to be able to contribute to the discussion. Besides, it was found that the students prefer to communicate in classroom discussions when the number of students is small as they feel less anxious and have more opportunities to communicate.

It should be mention that the teaching method used, i.e. Socratic Questioning, was an influencing factor as the students could express their opinions without being evaluated which helped them to overcome their fear of speaking. This made them more willing to communicate as agreed by the participants; therefore, the creative use of teaching method can be seen as an influential factor not only to students' WTC but to the study of factors affecting WTC as it is a method that makes the students more willing to participate in classroom discussions and, thus, allowing the researchers to find the factors that affect the students' willingness to communicate.

Besides, English competency has been seen as a factor that can influence students' participation in classroom. As the analysis has revealed, the students' perception of being competent in English language as well as the feeling of self-confidence in using the L2 enable them to convey their ideas and share their thoughts, whereas lack of competency may hinder their contributions, leading to a lower level of WTC. As a result, it can be anticipated from the findings that situational factors can be considered as mediation aspects which may influence students' WTC leading to its realization through language.

\subsection{Discourse Analysis: Linguistic Realization of WTC}

This section presents the discourse analysis of the observation transcripts to reveal linguistic means used by students to realize their WTC in the classroom. The focus here is on language choices made by the students during three discussion interaction sessions (IV, X, \& XI) to realize their WTC. Therefore, the study examined the interpersonal relationships including mood patterns and speech functions which enabled the researchers to identify the linguistic means employed by the students and to link them as the indicators of students' WTC. It should be mentioned that to gain a better understanding of the results and to facilitate the interpretation, the analysis of the findings is based on the interview data as well. The analysis of speech functions are presented below.

\subsubsection{Analysis of Speech Functions}

\subsubsection{Results of Speech Functions in Discussion Interaction IV}

The analysis of speech functions in discussion session IV was carried out to reveal the speakers' role as dominant or incidental, and to show how they expressed their ideas through linguistic means. The results are presented in Table 1 below: 
Table 1. Speech Functions in Discussion Interaction IV

\begin{tabular}{|c|c|c|c|c|c|c|c|}
\hline $\begin{array}{c}\text { Initiation of } \\
\text { speech function } \\
\text { (Discussion IV) }\end{array}$ & C. & E. & Q. & L. & R. & Y. & Total \\
\hline Statement & 5 & 5 & 1 & 4 & 0 & 4 & 19 \\
\hline Question & 13 & 14 & 1 & 4 & 1 & 15 & 48 \\
\hline Command & 1 & 0 & 0 & 1 & 2 & 1 & 5 \\
\hline Offer & 0 & 0 & 0 & 0 & 0 & 0 & 0 \\
\hline $\begin{array}{c}\text { Responding } \\
\text { Speech Function }\end{array}$ & & & & & & & \\
\hline Supporting & 17 & 40 & 2 & 0 & 4 & 36 & 99 \\
\hline Confronting & 2 & 2 & 1 & 0 & 3 & 2 & 10 \\
\hline Minor & 1 & 1 & 1 & 1 & 1 & 3 & 8 \\
\hline Total & 39 & 62 & 6 & 10 & 11 & 61 & 189 \\
\hline No. of turn & 26 & 43 & 6 & 5 & 10 & 39 & 129 \\
\hline
\end{tabular}

As shown in Table 1, students E. and Y. were the most dominant in discussion by producing more turns including 43 and 39, respectively. Moreover, most clauses were also produced by the students E. (62) and Y. (61). Student C. was the third most dominant speaker by producing 26 turns and 39 clauses, while the other students produced less turns and clauses in the discussions. The sheer volume of clauses produced by the students indicates their dominance in the discussion which suggests their greater willingness to communicate. The number of turns and moves produced by the students E. and Y. were almost similar and they both had almost equally the highest level of WTC in the discussion interactions. Furthermore, it was seen that the use of questions as the initiation of talk and the use of supporting reactions as the responding moves were the predominant speech functions employed by the students in the discussion classroom.

\subsubsection{Results of Speech Functions in Discussion Interaction $\mathrm{X}$}

The analysis of speech functions of data from discussion interactions $\mathrm{X}$ was carried out and presented in Table 2 below to show the students' use of linguistic choices which helped them to manifest their WTC.

Table 2. Speech Functions in Discussion Interaction $\mathrm{X}$

\begin{tabular}{|c|c|c|c|c|c|c|c|}
\hline \multirow{2}{*}{$\begin{array}{c}\text { Initiation of } \\
\text { speech function } \\
\text { (Discussion } \mathrm{X} \text { ) }\end{array}$} & \multicolumn{6}{|c|}{ Students } & \multirow[b]{2}{*}{ Total } \\
\hline & C. & E. & Q. & L. & $\mathrm{R}$. & Y. & \\
\hline Statement & 6 & 13 & 0 & 0 & 3 & 12 & 34 \\
\hline Question & 3 & 13 & 2 & 3 & 6 & 9 & 36 \\
\hline Command & 0 & 0 & 0 & 0 & 0 & 0 & 0 \\
\hline Offer & 0 & 0 & 0 & 0 & 0 & 0 & 0 \\
\hline \multicolumn{8}{|l|}{$\begin{array}{c}\text { Responding } \\
\text { Speech Function }\end{array}$} \\
\hline Supporting & 20 & 40 & 5 & 6 & 15 & 3 & 89 \\
\hline Confronting & 3 & 5 & 2 & 0 & 0 & 1 & 11 \\
\hline Minor & 2 & 0 & 0 & 0 & 0 & 1 & 3 \\
\hline Total & 34 & 71 & 9 & 9 & 23 & 26 & 173 \\
\hline No. of turn & 29 & 42 & 8 & 7 & 16 & 21 & 123 \\
\hline
\end{tabular}

As seen in Table 2, student E. dominated openings and responding speech functions by producing 42 turns and 71 clauses. It suggests that she was very willing to participate in discussions not only by initiating talk but by sustaining conversation through building supporting clauses. Student C. was the second highest active participant by producing 29 turns and 34 clauses. Students Y. and R. were the third and fourth willing participants in the discussion interactions. The least willing participants were Q. and L. producing the same number of clauses, 9. It was also revealed that there was a close similarity in the number of statements and questions produced by the students and they were the two dominant speech functions in the initiation move; however, questions were slightly used more. In responding reactions, the use of supporting moves was appeared to be more predominant.

\subsubsection{Results of Speech Functions in Discussion Interaction XI}

The study also focused on discussions XI to investigate the students' use of linguistic resources contributed to the manifestation of their WTC. The results are presented in Table 3:

Table 3. Speech Functions in Discussion Interaction XI

\begin{tabular}{|c|c|c|c|c|c|c|c|}
\hline \multirow{2}{*}{$\begin{array}{c}\text { Initiation of speech } \\
\text { function } \\
\text { (Discussion XI) }\end{array}$} & \multicolumn{5}{|c|}{ Students } & \multirow{2}{*}{ Total } \\
\cline { 2 - 7 } & C. & E. & Q. & L. & R. & Y. & \\
\hline Statement & 2 & 10 & 0 & 0 & 2 & 8 & 22 \\
\hline Question & 6 & 10 & 1 & 1 & 3 & 10 & 31 \\
\hline Command & 0 & 0 & 0 & 0 & 0 & 3 & 3 \\
\hline Offer & 0 & 0 & 0 & 0 & 0 & 0 & 0 \\
\hline $\begin{array}{c}\text { Responding Speech } \\
\text { Function }\end{array}$ & & & & & & & \\
\hline Supporting & 18 & 18 & 0 & 12 & 9 & 16 & 73 \\
\hline Confronting & 2 & 2 & 0 & 2 & 8 & 1 & 15 \\
\hline Minor & 1 & 1 & 0 & 0 & 1 & 0 & 3 \\
\hline Total & $\mathbf{2 9}$ & $\mathbf{4 1}$ & $\mathbf{1}$ & $\mathbf{1 5}$ & $\mathbf{2 3}$ & $\mathbf{3 8}$ & $\mathbf{1 4 7}$ \\
\hline No. of turn & 21 & 29 & 1 & 10 & 20 & 28 & 109 \\
\hline
\end{tabular}

As Table 3 shows, there is a close similarity in the number of turns taken by the students E. and Y. who were the most dominant participants. Moreover, the number of clauses produced by them indicates that with almost the same contributions they were the highest active participants by producing 41 and 38 clauses, respectively. Students C. and R. took almost the same number of turns with 21 and 20 turns, respectively; however, student C. produced more clauses, through which contributed to the maintenance of talk. The contribution of student L. was not high as she produced 10 turns and 15 clauses. Student Q. was the least active participant with almost no contributions except for producing only one turn and clause which can be due to her lack of experience and shared knowledge. Furthermore, the Table indicates that the predominant speech functions were questions in initiation move and supporting reactions in responsive 
move. It is also evident that all the students tended to react more through supporting moves rather than confronting moves which suggests a cooperative and positive atmosphere in the classroom.

Findings from speech functions counts demonstrated the level of students' participation and showed variation in utterances in the three discussion sessions. This reinforces the claim that there are certain situational factors that significantly impact students' WTC (Cao, \& Philp, 2006; Kang, 2005). Moreover, the extensive use of responsive moves suggest that the initiating move is not the only major indicator of learner's WTC as was asserted in the literature. Therefore, the results suggest that both initiating a talk and responding reactions can be regarded as the indicators of learner's WTC.

\subsubsection{Results of Mood Patterns}

To identify the mood patterns and the role of the students participating in classroom discussion interactions, the researchers collated and interpreted the results of the analysis of the observation transcripts of three discussion sessions, IV, X, and XI. The results showed that 361 turns and 509 clauses were produced by the students. Turns often consisted of multiple clauses; some students produced mostly a single clause per turn while others produced multiple clauses. The analysis revealed that students' WTC was realized linguistically through the predominant mood patterns of declarative and interrogative statements to exchange information and opinions as presented in Figure 2.

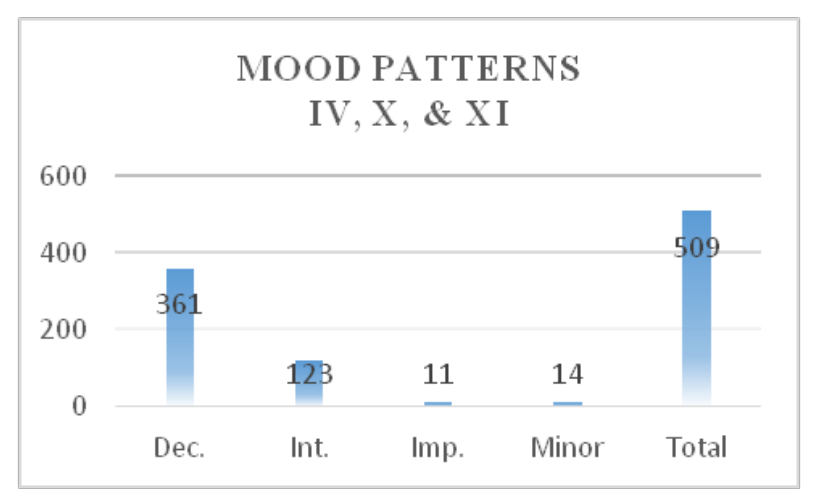

Figure 2. Mood Patterns of Discussion Interactions

As seen in Figure 2, in the three discussions inspected, students employed declaratives to a greater degree than interrogatives. Although, declarative mood was produced extensively in all the discussions, their use was predominant in supporting responses. This suggests that students tended to provide more support to their peers through information, elaboration and clarification. Minors were also used in small number to mainly provide positive feedback to the other speakers. Moreover, the small number of imperative mood emphasizes a friendly and supporting discussion atmosphere as the extensive use of it may constrain the students' opportunities to express their opinions and, thus, suppress the interactions. Therefore, as the findings suggest, interrogative and declarative moods provided more opportunities for the students to participate in the classroom discussions.

\subsection{Description of Linguistic Choices and Interpersonal Relationships}

The findings of linguistic analysis have shown that the opening moves for class discussions were dominated by questions; i.e. they initiated the discussions by asking questions regarding the topic with the intention of figuring out the other's opinions. Therefore, the dominated opening mood choice was interrogatives as shown in Figure 3 .

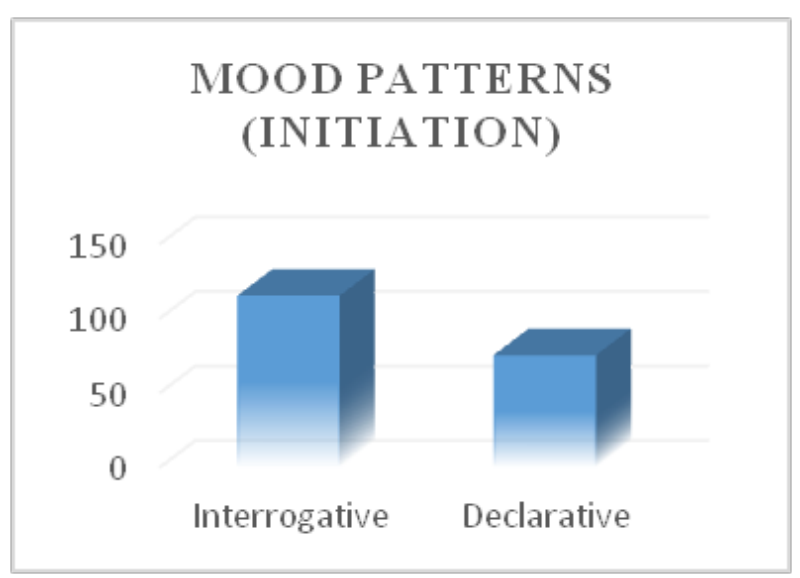

Figure 3. Predominant Mood Patterns in Initiation Moves

As seen in Figure 3, the interrogative mood was produced more as the initiation of talk as the aim of the course was to allow the students to ask questions about the topic of the discussions in order to be capable of making arguments which could contribute to their critical thinking skills. Demanding feedback and asking for ideas and information through interrogative mood can be regarded as the stimulation of the negotiations. Through interrogative mood students can encourage their peers to engage in discussions by providing their answers, opinions and thoughts on the questions, which suggests an encouraging factor for interlocutors to participate more in talk and this increases their WTC behavior in classroom discussions.

Whereas, in the responding move, statement was the most commonly used speech function in which students' negotiations occurred to provide opinions mostly through the use of statements. Therefore, the dominant mood was declarative which helped the students to participate in interactions and offer their ideas through statements and suggestions. Moreover, the findings have shown that the responding moves were mostly achieved through supports and just in few cases we can see confrontation among the students as presented in the Figure 4: 


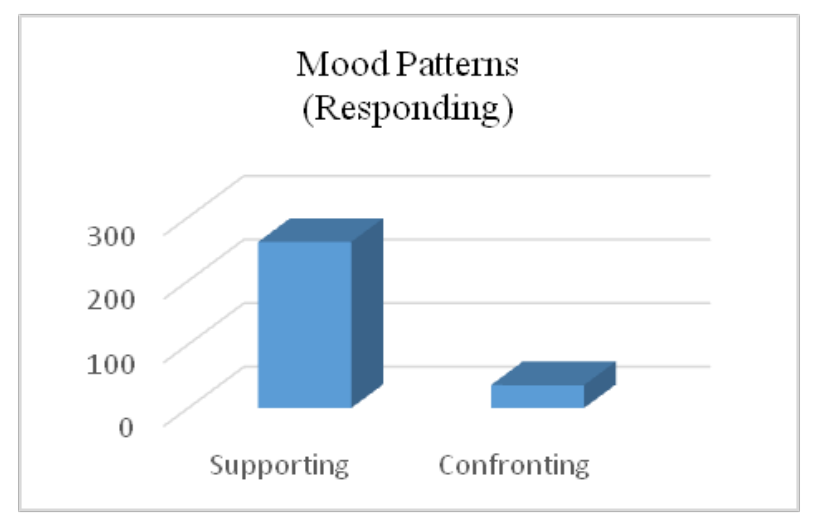

Figure 4. Predominant Mood Patterns in Responding Moves

As the findings show, declarative mood was mostly used in the form of supporting clauses and in few cases in confronting clauses. This suggests that declarative mood was used by the students to support their peers, especially through continuing move by producing more clauses to prolong their own talk, to share more ideas and information or through reacting to their peers' talk to provide supports and to develop utterances collaboratively. The use of the supporting move suggests a cooperative atmosphere in the classroom which helped students to maintain a positive atmosphere during interactions and, thus, increased their WTC in the classroom discussions.

As Eggins and Slade (1997) stated, conversation involves a continuous movement between building solidarity and discovering differences and this is true for the students' participation in this research as establishing solidarity was all straightforward among them since they had a quite intimate interaction although in some cases the differences of opinions were seen among them. The choice of speech functions suggests that the role relations among students was friendly and cooperative, thus the classroom situation was encouraging for discussions. Their contributions were mostly supported by their course mates and their turns were rarely interrupted; the information offered by a student was rarely challenged by the other students in the classroom. Instead, they used language choices which allowed them to exchange information, to provide their opinions and to make suggestions. It was a cooperative student-centered classroom with equal opportunities for all of them to negotiate information and a friendly environment for them to enjoy the discussions whether or not to have been actively engaged in interactions.

The frequency of participation was not equal among the students in all the discussions investigated. Some students did not participate much in the discussions. The student Q. contributed the least and produced less turns and clauses and this scarcity was due to her lack of actual experiences related to the topic which made her not being able to give her own opinions as she said in her interview, "probably, I'm still young compared to the others, so I don't have that much of exposure, that much of experience to relate them. So, that's why hold me back." She was also careful to participate in discussions as she took into account that her ideas might offend the others which made her to produce few clauses, taking care not to hurt her classmates as she stated, "I'm afraid that the way I express my ideas, probably will cause some misunderstanding because I know my words are quite direct and if I really follow what I say, it definitely hurts someone.” According to her, her classmates had been more prepared for discussions as they were older than her with exposures to more experiences which help them to relate the topic of the story to real life situations and, thus, to enable them to participate more.

However, some students played the role of the dominant speakers as they had the power to control the conversation by taking more turns and producing more clauses in each turn. The student E. was appeared to be the most dominant speaker in terms of the number of turns and clauses since the number of her contributions was high. The significance of this fact is that she was more willing to communicate in the class discussion interactions and as she mentioned in her interview the reasons were "the topics, the subject itself, the lecturer" and the rapport that she had with her classmates.

It should be mentioned that being dominant does not suggest power relations in this research and does not support Egging and Slade's (1997) suggestion that the dominant speaker is the most powerful to control the direction of a conversation since there was no evidence of imperative moods in negotiations among the students except in few cases which suggests that no one attempted to command their course mates and to have power and influence over them. Instead, the cooperation role among them was seen through asking, answering developing and co-constructing each other's interactions which everyone had the equal chance of participations.

Thus, the dominant speaker can be regarded either as an assertive initiator as the ability "to initiate conversations," "to make requests," "to express positive or negative personal rights and feelings" or the "capacity to maintain conversations" are instances of assertive behavior of a speaker (Richmond \& McCroskey, 1985, p. 92), or as supportive, cooperative and encouraging responder who provides supports through replies (Cao, 2009; Weaver, 2007).

\section{Conclusions}

The limitations of this study should also be noted. The primary limitation would be the use of a small sample size. Moreover, since this study utilized non-randomized sampling and it is concerned only with the classroom discussion interactions, the findings of the study cannot be generalized to other contexts. However, the results could still contribute to the body of classroom-based research in 
the area, and the in-depth analysis of the participants' linguistic strategies and interview necessitates the use of a small sample size.

Despite these limitations, the study revealed the emergent factors that increased the students' contributions and WTC in the discussion interactions which confirms the claim that situational factors affect students' WTC (Cao \& Philp, 2006; Kang, 2005). The influencing factors of WTC that emerged in the study include topics of interest, relevance of the topic to one's experience, teaching method, the relationship with peers, peers' points of view, the role of the moderator, positive feedback, motivation to improve English language proficiency, familiarity with peers, the size of the class, English competency and the fear of being ridiculed/judged. It can be anticipated that these factors can help to engender in students the willingness to communicate in the classroom context using linguistic means.

As the language is important in order to realize WTC, the study examined the data to discover how students employed linguistic means to communicate with each other. In terms of turns and speech functions, the study showed that the more willing students took more turns and produced more clauses to keep their interactions going. This suggests that situational factors not only can affect students' WTC, but they contribute to the length of the interactions leading to the production of more utterances. As the students could relate the topic of the discussion to their real life situation, they could use the genre of storytelling and produce more utterances. Besides, it was shown that both the initiation of speech and the responding reactions by the learners are indicators of their WTC. Therefore, it can be concluded that situational factors affect students' WTC in a way that they encourage students not only to initiate interactions but to respond to interactions through linguistic means.

Moreover, students' interpersonal relationships such as peers' help and support as well as the positive classroom environment affect their participation (Cao \& Philp, 2006; MacIntyre, 2007) and motivate them to engage more in the discussions (Ismail, Abd Rahman \& Othman, 2020). The findings in the current study also indicate that WTC is affected by interpersonal relationships among interlocutors through linguistic choices and situational factors. Thus, this study can provide insights into an understanding of linguistic resources and situational factors which contribute to the learners' participation in the classroom discussion interactions.

\section{REFERENCES}

[1] Abd Rahman, S. N., Abd. Samad, A., \& Abu Bakar, N. (2020). Exploring learners' perception on improving their willingness to communicate in English through experiential learning among undergraduate students. Universal Journal of Educational Research, 8(1A), 62-69.

[2] Braun, V. \& Clarke, V. (2006). Using thematic analysis in psychology. Qualitative Research in Psychology, 3, 77-101.

[3] Cao, Y. (2009). Understanding the notion of interdependence, and the dynamics of willingness to communicate, Doctoral

dissertation. Retrieved from https://researchspace.auckland. ac.nz/handle/2292/5584

[4] Cao, Y., \& Philp, J. (2006). Interactional context and willingness to communicate: A comparison of behavior in whole class, group and dyadic interaction. System, 34, 480-493.

[5] Creswell, J. W. (2008). Educational research: planning, conducting, and evaluating quantitative and qualitative research (3rd ed.). New Jersey: Pearson Prentice Hall.

[6] Darmi, R., Albion, P. (2014). Assessing the language anxiety of Malaysian undergraduate English language learners. Proceeding of the Global Conference on Language Practice \& Information Technology, 1-10.

[7] Dörnyei, Z., \& Kormos, J. (2000). The role of individual and social variables in oral task performance. Language Teaching Research, 4, 275-300.

[8] Eggins, S., \& Slade, D. (1997). Analyzing causal conversation. London: Equinox.

[9] Eggins, S., \& Slade, D. (2004). Analyzing causal conversation (2nd ed.). London: Equinox.

[10] Halliday, M. A. K. (1985). An introduction to functional grammar. London: Arnold.

[11] Halliday, M. A. K. (1994). An introduction to functional grammar (2nd ed.). London: Arnold.

[12] Ismail, L., Abd. Rahman, F., \& Othman, M. (2020). Effectiveness of using a tracker chart to enhance willingness to communicate among ESL learners in a philosophical inquiry classroom discussion. Pertanika Journal of Social Sciences and Humanities, 28(S2), 233-245.

[13] Kho-Yar, A. S., Rafik-Galea, S., \& Kho, E. A. H. (2018). Willingness to communicate in English among ESL undergraduates in Malaysia. Journal of Cognitive Sciences and Human Development, 4(1), 28-34.

[14] Jacob, G., \& Ward, C. (2000). Analyzing student-student interaction from cooperative learning and systemic functional perspectives. [Electronic version]. Electronic Journals of Science Education, 44(4). Retrieved fromhttp://ejse.southw estern.edu/article/view/7639/5406

[15] Kang, S. (2005). Dynamic emergence of situational willingness to communicate in a second language. System, $33,277-292$

[16] Lincoln, Y., \& Guba, E. (1985). Naturalistic inquiry. London: Sage.

[17] MacIntyre, P. D. (2007). Willingness to communicate in the second language: Understanding the decision to speak as a volitional process. The Modern Language Journal, 91(iv), 564-576. 
[18] MacIntyre, P. D., \& Doucette, J. (2010). Willingness to communicate and action control. System, 38(2), 161-171.

[19] MacIntyre, P. D., Baker, S., Clément, R., Conrod, S. (2001). Willingness to communicate, social support and language learning orientations of immersion students. Studies in Second Language Acquisition 23, 369-388.

[20] MacIntyre, P. D., Clément, R., Dörnyei, Z., \& Noels, K. A. (1998). Conceptualizing willingness to communicate in a L2: A situational model of L2 confidence and affiliation. The Modern Language Journal, 82, 545-562.

[21] Manipuspika, Y. S. (2018). Correlation between anxiety and willingness to communicate in the Indonesian EFL context. Arab World English Journal, 9 (2). DOI: https://dx.doi.org/10.24093/awej/vo19no2.14

[22] McNabb, E. D. (2015). Case Research in Public Management. London \& New York: Routledge.

[23] McCroskey, J. C., \& Baer, J. E. (1985). Willingness to communicate: The construct and its measurement. Paper presented at the annual convention of the speech communication association, Denver, CO.

[24] Miles, M. B., \& Huberman, M. A. (1994). Qualitative data analysis: A sourcebook of new methods. Baverly Hills, CA: Sage.

[25] Muller, N., \& Willson, B. (2008). Collaborating role construction in a conversation with dementia: An application of systemic functional linguistics. Clinical linguistics \& Phonetics, 22(10-11), 767-774.

[26] Nair, S. K. G., Rahim A. R., Setia, R., Husin N., Sabapathy, E., Abd Jalil, A. N., Mohd Razlan, R., Mohamad, R., Mat So'od, M. S., Md Yusoff, I. N., Madihah Mohamed, M. N., \& Abu Seman, N. (2012). Asian Social Science, 8(4), 143-147.

[27] Nakatani, Y. (2006). Developing an oral communication strategy inventory. The Modern Language Journal, 90(2), 151-168. http://dx.doi.org/10.1111/j.15404781.2006.00390.x

[28] Omar, H., Embi, A. M., \& Yunus, M. M. (2012). Learners' use of communication strategies in an online discussion via Facebook. International Educational Technology Conference IETC2012. Procedia-Social and Behavioral Sciences, 64, 535-544.

[29] Riasati, M. J. (2018). Willingness to speak English among foreign language learners: A causal model, Mohammad Cogent Education (2018), 5: 1455332. https://www.tandfon line.com/loi/oaed20

[30] Riasati, M. J., \& Noordin, N. (2011). Antecedent of willingness to communicate: A review of literature. Studies in Language and Literature, 3(1), 74-80.

[31] Richmond V. P., \& McCroskey J. C. (1985). Communication: Apprehension, Avoidance, and Effectiveness. Scottsdale, AZ: Gorsuch Scarisbrick.

[32] Robson, G. G. (2015). A model of situational constructs accounting for willingness to communicate at a Japanese university. (Ph.D. thesis) Temple University Graduate Board.

[33] Weaver, C. (2007). Willingness to communicate: A mediating factor in the interaction between learners and tasks. In K. Van den Branden, K. Van Gorp, \& M. Verhelst (Eds.), Tasks in action: Task-based language education from a classroom-based perspective (pp. 159-194). Cambridge: Cambridge Scholars Press.

[34] Yashima, T., MacIntyre, P. D., \& Ikeda, M. (2018). Situated willingness to communicate in an L2: Interplay of individual characteristics and context. Language Teaching Research, 22, 115-137. DOI: https://doi. org/10.1177/1362168816657851

[35] Yousef, R., Jamil, H., \& Razak, N. (2013). Willingness to communicate in English: A study of Malaysian pre-service English teachers. English Language Teaching, 6(9), 205-216. 